\title{
The Relation of Perceived Family Distress to Forgiveness, Hope, and Life Satisfaction Among Indonesian Vocational High School Students
}

\author{
$1^{\text {st }}$ Amalia Rahmandani* \\ Faculty of Psychology \\ Diponegoro University \\ Semarang, Indonesia \\ a.rahmandani@live.undip.ac.id
}

\author{
$2^{\text {nd }}$ Yohanis Franz La Kahija \\ Faculty of Psychology \\ Diponegoro University \\ Semarang, Indonesia \\ franzlakahija@gmail.com
}

\author{
$4^{\text {th }}$ Lusi Nur Ardhiani \\ Faculty of Psychology \\ Diponegoro University \\ Semarang, Indonesia \\ 1.ardhiani@gmail.com
}

\author{
$3^{\text {rd }}$ Hastaning Sakti \\ Faculty of Psychology \\ Diponegoro University \\ Semarang, Indonesia \\ sakti.hasta@gmail.com
}

\begin{abstract}
Forgiveness, hope, and satisfaction with life are areas of study in positive psychology, as well as the determinants of mental health in adolescents with family distress experiences. This study aims to investigate the relation of perceived family distress to forgiveness, hope, and satisfaction with life among Indonesian adolescents. Participants were 909 Indonesian students at a vocational high school $\left(\mathrm{M}_{\text {Age }}=15.93 ; \quad \mathrm{SD}_{\mathrm{Age}}=.909 ; \quad\right.$ male=60.3\%; female $=39.7 \%$ ). Perceived family distress was measured with the Brief Family Distress Scale and mental health conditions were examined using the Forgiveness Scale, the State Hope Scale, and the Satisfaction with Life Scale. Data were analyzed using Spearman's rho correlation. The results showed that perceived family distress was negatively and significantly related to forgiveness, hope, and satisfaction with life. The three dimensions of forgiveness (self, others, and situations) and agency subscale of hope were negatively predicted by the perceived family distress, but not on the pathway's subscale of hope. While perceived family distress had a weaker relationship with selfforgiveness in male teenagers, perceived family distress in female teenagers was not significantly related to the forgiveness of others. Hope and its agency subscale in male teenagers were not significantly related to perceived family distress, but those correlations in female teenagers showed significant relationships. Both male and female teenagers showed no significant relationship between perceived family distress and the pathways subscale of hope. Forgiveness, hope, and satisfaction with life when analyzed in pairs had a positive and significant relationship. Compared to male teenagers, forgiveness in female teenagers played a greater role in increasing hope and satisfaction with life.
\end{abstract}

Keywords- family distress, positive psychology, adolescents, collectivistic culture, Indonesia

\section{INTRODUCTION}

Forgiveness, hope, and life satisfaction are scientifically proven as predictors of well-being in life including in adolescents $[1,4]$. Adolescents are faced with conditions that require radical adjustment due to changes in physical, psychological, cultural, and social elements as they get older, along with the increase in the social role and expectations in life [5]. In addition to the problems faced as a result of continuous change in terms of physical and psychological aspects, the burden to be able to carry out roles and meet social demands seems to be important in increasing adolescents' mental health problem. Research by Kieling et al. indicated that one in five adolescents worldwide is suffering mental health problem [6]. Along with this condition, the past few decades have been believed to be the importance period of the contribution of various research in positive psychology for mental health of individuals [3], [7]. A recent research showed evidence that forgiveness can improve individual psychological well-being [7]. Forgiveness was also found as a significant predictor of subjective happiness among adolescents [4]. Other research also showed evidence that there is positive correlation between hope, optimism, and life satisfaction among adolescence [5]. Those with higher hope are more affirmative with their goals and tend to be satisfied with what have been achieved in life $[8,9]$. It cannot be denied that the ability of adolescents to develop their psychological wellness is a struggle with a lot of obstacles. One of the most important factors that influences adolescents' durable and personal strengths is the family. 
Previous research publications about perceived family distress and negative emotional states showed that perceived family distress was positively related to depression, anxiety, and stress among adolescents [10]. Furthermore, other research concluded that most mental health problems diagnosed in adulthood begin in adolescence [11]. To improve mental health, encouraging efforts to reduce negative emotional states alone will not be enough, several studies concluded that there are two ways of maintaining well-being which are reducing level of negative affect and increasing level of positive affect [12]. Fredricsons' finding as in [12] also concluded that positive emotions may also broaden people's mindsets and build their personal psychological resources endurance. So research on positive attributes within oneself, in this case forgiveness, hope, and satisfaction with life, deserve to be examined. We also need to know how these attributes were influenced by perceived family distress. This study aimed to examine the associations between perceived family distress with forgiveness, hope, and satisfaction with life among Indonesian adolescents.

\section{METHODS}

This research was conducted using a quantitative method. The data collection was carried out crosssectionally. Researchers hypothesized that perceived family distress would negatively correlate with forgiveness, hope, and satisfaction with life. Further analysis was also carried out to obtain a more comprehensive picture of the differences in correlations among variables in this study.

\section{A. Participants}

Participants in this study were obtained through proportionate cluster random sampling involving 909 grade X, XI, and XII from a vocational high school in Semarang, Indonesia. Only half of class XII students were included in this study because the other half were undergoing an internship for 1 semester. All subjects were between 14 and 18 years $\left(\mathrm{M}_{\mathrm{Age}}=15.93 ; \mathrm{SD}_{\mathrm{Age}}=.909\right)$, consisting of 548 males $(60.3 \%)$ and 361 females $(39.7 \%)$. Students of vocational high school was chosen because, as in [13] that the decision of students to take vocational education is determined by family limitations.

\section{B. Measures}

Perceived Family Distress. This study measured perceived family distress using the Indonesian version of The Brief Family Distress Scale (BFDS) [14]. BFDS was originally developed in families with children with autism. BFDS was used by taking into account the use of language which was considered possible to be used in more general situations. BFDS is a single item scale with a 10-point scale response regarding family crisis. Participants were asked to rate where they and their families were in terms of crisis. Each point is grounded in the statement describing a point along the continuum from no stress to complete crisis. There are four crisis groups of responses on this scale, namely the 'no impairment' group or have a normal level of perceived family distress (responding 1 to 3 ), the 'moderate impairment' group or being in the category of nonreferred level of distress (responding 4 to 5), and the 'marked impairment' groups are divided into the close to crisis group (responding 6 to 7 ) and the crisis group (responding 8 to 10 ).

Forgiveness. Forgiveness was measured using a 40-item scale of forgiveness developed by researchers based on [15], divided into 3 subscales: self-forgiveness, forgiveness of others, and forgiveness of situation. This forgiveness scale is commonly used in adolescent participants as in [16]. Reference [15] explains that forgiveness is a dialectical process through which people synthesize their prior assumptions and the reality of the transgression into a new understanding of the transgression, transgressors, transgression sequences, and, potentially, of themselves, other people, or the world. In cases involving the forgiveness of another person, the forgiver may develop benevolent and positive feelings for the person forgiven; while the situations referred to in forgiveness of situations are situations that violate a person's positive assumptions and lead to negative responses to those situations. The Cronbach's alpha of forgiveness scale in this study were .867 . This is a Likert scale consisting of four response categories, namely Strongly Disagree, Disagree, Agree, and Strongly Agree. Scores on favorable items, sequentially scored 0 , 1, 2, and, 3; while

scores on unfavorable items were scored $3,2,1$, and 0 . In this study, forgiveness scores were then grouped into a five- level category based on hypothetical norms, i.e. 'very low' $(\mathrm{x} \leq 30), \quad$ 'low' $(50 \geq \mathrm{x}>30), \quad$ 'moderate' $(70 \geq x>50)$, 'high' (90 $\geq x>70)$, and 'very high' ( $x>90)$.

Hope. Hope in this study was measured using The State Hope Scale [17] which is used up to the present study in adolescence as in [18]. The State Hope Scale is a six-item scale that describes a cognitive set that is based on a reciprocally derived sense of successful agency (goal- directed determination) and pathways (planning to meet goals). Agency taps the individual's perceived capacity for initiating and maintaining the actions necessary to reach a goal. While pathways tap the perceived ability to generate routes to one's goals [17]. Before using it, an adaptation into Indonesian language was conducted and Cronbach $\alpha$ in this study population was .701. Respondents were instructed to take a few moments to focus on what was going on in their lives when they filled in the scale and selected the number that best described how they thought about themselves and put that number in the blank provided (on an 8-point scale, with $1=$ Definitely False, $2=$ Mostly False, 3 = Somewhat False, $4=$ Slightly False, 5 = Slightly True, 6 = Somewhat True, $7=$ Mostly True, and $8=$ Definitely True). The even- numbered items were agency, and the odd-numbered items were pathways. Subscale scores for agency or pathways were derived by adding the three even- and odd-numbered items, and the total State Hope Scale score was the sum of all six items. In this study, the state hope scores were then grouped into a five-level category based on hypothetical norms, i.e. 'very low' ( $x<18)$, 'low' (24>x $\geq 18)$, 'moderate' (31>x $\geq 24)$, 'high' (38>x $\geq 31)$, and 'very high' ( $\mathrm{x} \geq 38)$.

Satisfaction with Life. Life satisfaction was measured using The Satisfaction with Life Scale (SWLS) [19] which is commonly used in research conducted to adolescents as in [20]. The SWLS is a five-item scale designed to assess a person's global judgment of life 
satisfaction, which is theoretically predicted to depend on a comparison of life circumstances to one's standards [21]. Previously, the psychometrics properties of this scale among adolescents' sample had been examined [22]. An adaptation into Indonesian was conducted before using the scale and Cronbach $\alpha$ in this study population was .733. Participants had to choose one of the seven-point scale that indicated participants' agreement of each item, namely $1=$ strongly disagree, 2 $=$ disagree, $3=$ slightly disagree, $4=$ neither agree nor disagree, $5=$ slightly agree, $6=$ agree , and $7=$ strongly agree. The total number of all scores was the final result of the scale. In this study, satisfaction with life scores were then grouped into a five-level category based on hypothetical norms, i.e. 'very low' $(x<13)$, 'low'

consent voluntarily before engaging in research data collection activities. Participants responded manually to the booklet containing psychological scales immediately after distribution and completed within 15-30 minutes.

\section{Data Analysis}

The examination of correlations in this study was conducted with non-parametric statistics using Spearman's rho. This test was done by considering that all variables were not normally distributed based on the results of the Kolmogorov-Smirnov Test. Non-parametric statistical difference tests using the Wilcoxon T-Test were also carried out to examine further differences within groups inter- dimensions of forgiveness and intersubscales of hope. Data were also processed using descriptive statistics, namely crosstab analysis of perceived family distress with other psychological variables. All data processing was carried out using version 22 of the Statistical Package for the Social Sciences (SPSS) program.

\section{RESULTS}

\section{A. Correlation of Perceived Family Distress with Forgiveness, Hope, and Satisfaction with Life}

The results of the correlation examination of the relation of perceived family distress to forgiveness, hope, and satisfaction with life without or with controlling for sex are listed in Table 1 . Table 1 also presents the mean and standard deviation of each psychological variable. Spearman's rhotest was conducted and found a significant negative correlation between perceived family distress with positive psychological variables, in this case forgiveness, hope, and satisfaction with life. Specifically, perceived family distress also has significant negative correlations with the three dimensions of forgiveness, namely self-forgiveness, forgiveness of others, and forgiveness of the situation, as well as agency subscale of hope. All these results are significantly correlated at the .01 level with the strength of correlations $\left(\mathrm{r}_{\mathrm{xy}}\right)$ varying from weak to moderate, ranging from .103 to .325 [23]. Different results were shown while

testing the relationship between perceived family distress and pathways subscale of hope in which an insignificant negative correlation is obtained $\left(\mathrm{r}_{\mathrm{xy}}=.052\right)$. The correlation is only significant at .05 level after controlling for sex $\left(\mathrm{r}_{\mathrm{xy}}=.083\right)$. All correlations among positive psychological variables in general as well as by (18>x $\geq 13)$, 'moderate' ( $23>x \geq 18)$, 'high' ( $28>x \geq 23)$, and 'very high' $(\mathrm{x} \geq 28)$.

\section{Procedure}

Researchers conducted a literature study and then submitted a research permit to a public vocational high school in Semarang, the capital of Central Java, Indonesia. Proportionate cluster random sampling was conducted to obtain participants by considering the proportion of students in grades X, XI, and XII. The total population of students in class XII involved in this study was half of the total because the other half was undergoing an internship for one semester. To meet ethical standards, participants signed informed

their dimensions and subscales are positively and significantly related at .01 level without or with controlling for sex.

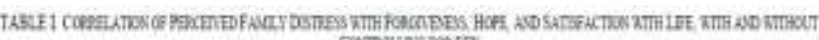

\begin{tabular}{|c|c|c|c|c|c|c|c|c|}
\hline & 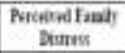 & 1 & la & b & It & : & $\mathbf{a}$ & $3 b$ \\
\hline \multicolumn{9}{|l|}{ 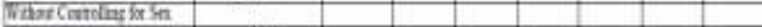 } \\
\hline 1. Foppunes & $-2 \pi^{11}$ & & & & & & & \\
\hline 1 set & $-10^{\prime \prime}$ & 505 & & & & & & \\
\hline $10 \mathrm{mn}$ & $-133^{\prime \prime}$ & $7 E^{2}$ & $231^{\prime \prime}$ & & & & & \\
\hline$c \sin n \pi$ & $\mathrm{Mi}$ & आले & $50 \mathrm{~N}^{\prime \prime}$ & Ait & & & & \\
\hline 2 Hasp & -.125 & $275^{\circ}$ & $251^{\prime \prime}$ & $x^{n}$ & $233^{m}$ & & & \\
\hline 2 imant & 18 & 215 & यो & $165^{\prime \prime}$ & 1124 & $8 e^{2}$ & & \\
\hline theren & -652 & $277^{2}$ & $233^{\prime \prime}$ & $215^{\prime \prime}$ & $2 f^{2}$ & झा" & $3 N^{2}$ & \\
\hline 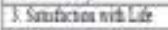 & $3 \pi^{2}$ & 256 & $22 \%$ & $.116^{\prime \prime}$ & $2 \pi$ & 64 & $A 5^{2}$ & Wक \\
\hline \multicolumn{9}{|l|}{ Wraceorting batser } \\
\hline 1. Fopmeit & $22 \%$ & & & & & & & \\
\hline 1 सी & -795 & क्रा & & & & & & \\
\hline Toten & -201 & NS" & 291 & & & & & \\
\hline C5onsen & स्षा & 355 & 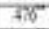 & An & & & & \\
\hline 2 Hope & $-13^{2}$ & 3211 & $2 \times 1$ & 32 & In" & & & \\
\hline 2. Aleaxy & $-1 y^{2}$ & 262 & $25 \%$ & $167^{7}$ & $2 y^{\prime \prime}$ & $85 i^{\prime \prime}$ & & \\
\hline 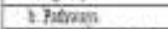 & $\overrightarrow{103}$ & अणन & $22^{4}$ & 23 & $3 e^{4}$ & sरा" & $54]^{3}$ & \\
\hline 3. Subetin nintLg & $-323^{\prime \prime}$ & 245 & $31 t^{n}$ & $144^{n}$ & $25^{4}$ & $4 \pi^{n}$ & S12 & IIS \\
\hline Mn & UI & हैकी & $4 \pi$ & उ्रत्र & 2191 & $5 x$ & IIT) & 3676 \\
\hline Sunded Dentino & 1.65 & 12.14 & 4373 & 5ख़ा & 5220 & 6020 & $34+8$ & 6009 \\
\hline
\end{tabular}

\section{B. Differences of Correlation between Male and Female Teenagers}

Examination using Spearman's rho was also carried out to see how the correlation among variables in male teenagers compared to female teenagers as shown in Table 2. In terms of the correlation between perceived family distress and self- forgiveness, male teenagers show a weaker relationship than female teenagers $\left(r_{x y}\right.$ male $=.093, \mathrm{p}<.05 ; \mathrm{r}_{\mathrm{xy}}$ female $\left.=.173, \mathrm{p}<.01\right)$. In terms of the correlation between perceived family distress and forgiveness of others, male teenagers show a significant relationship but not in female teenagers $\left(r_{x y}\right.$ male $=.151$, $\mathrm{p}<.01 ; \mathrm{r}_{\mathrm{xy}}$ female $\left.=.088, \mathrm{p}>.05\right)$. Whereas in terms of the correlation between perceived family distress and forgiveness of situations, male teenagers show a weaker relationship than female teenagers $\left(\mathrm{r}_{\mathrm{xy}}\right.$ male $=.149, \mathrm{p}<.01$; $\mathrm{r}_{\mathrm{xy}}$ female $\left.=.219, \mathrm{p}<.01\right)$. In addition, perceived family distress in female teenagers is significantly related to hope, but not in male teenagers $\left(\mathrm{r}_{\mathrm{xy} \text { male }}=.059, \mathrm{p}>.05 ; \mathrm{r}_{\mathrm{xy}}\right.$ female $=.151, \mathrm{p}<.01)$. This also applies to agency subscale of hope $\left(r_{x y}\right.$ male $=.073, p>.05 ; r_{x y}$ female $\left.=.201, p<.01\right)$; but in the pathways subscale of hope, both male and female teenagers do not show a significant correlation with perceived family distress $\left(r_{x y}\right.$ male $=.033, p>.05 ; r_{x y}$ female $=.060, \mathrm{p}>.05)$. In terms of the correlation between perceived family distress and satisfaction with life, both male and female teenagers show a significant correlation at.01 level where the correlation in female is stronger 
than male $\left(r_{x y \text { male }}=.236, p<.01 ; r_{x y}\right.$ female $\left.=.362, p>.05\right)$. Finally, the significance of the correlation between positive psychological constructs in general and based on their dimensions and subscales, both male and female teenagers, are all significant at.01 level, except for the correlation between forgiveness of situations

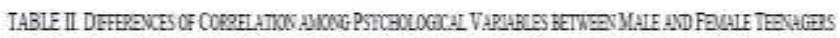

\begin{tabular}{|c|c|c|c|c|c|c|c|c|}
\hline & $\begin{array}{c}\text { Peroined Farilt } \\
\text { Distress }\end{array}$ & 1 & la & lb & le & 2 & $2 a$ & 13 \\
\hline \multicolumn{9}{|l|}{ Maik } \\
\hline 1. Forgiveness & $-179^{\prime \prime}$ & & & & & & & \\
\hline 2. Self & $-\left(M^{2}\right)^{2}$ & 570 & & & & & & \\
\hline b. Others & $-151^{\prime \prime}$ & $760^{\circ}$ & $262^{\prime \prime}$ & & & & & \\
\hline c. Stuativas & $-149^{\prime \prime}$ & $312^{2}$ & $423^{\prime \prime}$ & $.43^{2}$ & & & & \\
\hline 2. Hoxe & -0159 & $210^{\prime \prime}$ & $21 t^{\prime \prime}$ & $.176^{\prime \prime}$ & $.129^{\prime \prime}$ & & & \\
\hline 2. Ageny & -073 & $178^{\prime}$ & $197^{17}$ & $144^{-}$ & $.1188^{\prime \prime}$ & $871^{21}$ & & \\
\hline b hunays & -0.033 & .155 & $195^{\prime \prime}$ & 168 & $.11 \mathrm{I}^{\prime \prime}$ & $874^{\prime \prime}$ & $540^{\circ}$ & \\
\hline 3. Srisfaction wifl life & $-236^{\prime \prime}$ & $.161^{-}$ & $143^{\prime \prime}$ & .107 & $.1288^{\prime \prime}$ & $42^{2}$ & $487^{\prime \prime}$ & $299^{\prime \prime}$ \\
\hline \multicolumn{9}{|l|}{ Fenale } \\
\hline 1. Furgiveness & $-154^{\prime \prime}$ & & & & & & & \\
\hline 2. Self & $-1773^{\prime \prime}$ & 515 & & & & & & \\
\hline b. Oties & -088 & $732^{\prime \prime}$ & $189^{\prime \prime}$ & & & & & \\
\hline c. Strations & $-219^{\prime \prime}$ & $356^{\circ}$ & $553^{\prime \prime}$ & $+12^{\prime \prime}$ & & & & \\
\hline 1. Hxpe & $-151^{\prime \prime}$ & $339^{-1}$ & $175^{n}$ & $231^{\prime}$ & $.333^{\prime \prime}$ & & & \\
\hline 2. Agen 7 & $-191^{\prime \prime}$ & $254^{\prime \prime}$ & $333^{\prime \prime}$ & $138^{\prime}$ & $252^{\prime \prime}$ & $864^{\prime \prime}$ & & \\
\hline b. Potrnzys & -060 & $345^{2}$ & $247^{\prime \prime}$ & $272^{*}$ & $319^{1 "}$ & $849^{2}$ & $.44^{2}$ & \\
\hline 3. Sansfaction mifl Life & $-362^{\prime \prime}$ & $221^{\prime \prime}$ & $252^{\prime \prime}$ & $.110^{\circ}$ & $233^{\prime \prime}$ & $50^{\prime \prime}$ & $499^{\circ}$ & $283^{\prime \prime}$ \\
\hline
\end{tabular}

*. Correlation is significant at the .05 level (2-tailed).

**. Correlation is significant at the .01 level (2-tailed)

with satisfaction with life which is only significant at.05 level. Based on Table 2, it is also found that forgiveness in female teenagers plays a greater role than male teenagers for hope and satisfaction with life.

\section{The Examination of Score Differences among the Dimensions of Forgiveness and among the Subscales of Hope}

Based on the correlation examination in Tables 1 and 2, a typical result is obtained that is the correlation between perceived family distress with forgiveness dimensions and hope subscales. Based on this, further testing is carried out to see the differences in scores within the subjects' inter- dimensions of forgiveness and intersubscales of hope. The first step taken is to calculate the mean score per item on the forgiveness scale considering the differences in the number of items so that the mean self-forgiveness is $1.73(\mathrm{SD}=.312)$, the mean forgiveness of others is $1.80(\mathrm{SD}=.350)$, and the mean forgiveness of situations is $1.69 \quad(\mathrm{SD}=.401)$. While the mean and standard deviation of the hope subscales is obtained from the same number of items per subscale (each of three items), the mean agency subscale is $17.73(\mathrm{SD}=3,548)$ and the mean pathways subscale is $18.53(\mathrm{SD}=3,325)$.

The results of the examination of difference in scores within the subjects' inter-dimensions of forgiveness and inter-subscales of hope using the Wilcoxon T-Test show the significant differences inter-dimensions of forgiveness and inter-subscales of hope. Forgiveness of others is significantly higher than self-forgiveness $(\mathrm{Z}=5.737 ; \mathrm{p}=.000)$ and forgiveness of situations $(\mathrm{Z}=8.823 ; \mathrm{p}=.000), \quad$ self-forgiveness is significantly higher than forgiveness of situations $(Z=2.744 ; p=.006)$, so forgiveness of situations has the lowest significant value compared to the other two dimensions. Whereas in terms of hope, the pathways subscale is significantly higher than the agency subscale $(\mathrm{Z}=7.275 ; \mathrm{p}=.000)$.
These results may explain variations of differences in correlation between perceived family distress with these dimensions and subscales although in general, the results are shown to be negatively and significantly correlated.

\section{Results of Crosstabs Analysis of Perceived \\ Family Distress with Other Psychological Variables}

Cross tabulations analysis was also carried out to see the distribution of data at each level of perceived family distress according to the categorization of each psychological variable (Table 3) which showed quite varied results. In a dummy manner, there is a trend like the normal distribution in each category of perceived family distress when viewed from the category of satisfaction with life and forgiveness, both in general and in its dimensions. This trend is shown by an increase in the medium-high category (the majority of participants in the medium-high category), then a decrease in the high-very high category.

In contrast to forgiveness and satisfaction with life, the number of participants in the category of hope in general and by subscale shows a continuous increase from very low to very high at each level of perceived family distress (the majority of participants are in the very high category). In fact, this applies to those who appraise themselves and their families near crisis or are in crisis; the largest percentage of participants with a hope score, or according to their subscales, remained in the very high category.

\section{DISCUSSION}

The results of this study prove the hypothesis that there are negative and significant correlations between perceived family distress and forgiveness (and in its three dimensions namely self, others, and situations), hope, and satisfaction with life. Direct support for the result that perceived family distress is negatively associated with adolescents' forgiveness has not been found by researchers in recent studies. However some previous studies that include the family role in encouraging forgiveness have supported this study e.g. family communication patterns are negatively associated to motivation to revenge [24] or intervention study involving family roles cam encourage forgiveness in adolescents who did a self-injury [25], in addition to other studies that oppose it (e.g. perceived positive parenting style is not associated to the tendency of adolescents to forgive [26]). Other studies have sensitively distinguished the influence of maternal

forgiveness that has a greater role in the forgiveness and mental health of adolescents (e.g. Denham et al.; Mullet, Rivière, Muñoz Sastre in [27]; [28]). Previous studies indirectly support the relationship between perceived family distress and hope as in [29] that explains the relationship between family cohesion and hope in children, and their contribution to loneliness as a risk factor and the sense of the coherence as a protective factor, or in [30] that explains the relationship between family connections and hope in early adolescents. Whereas support for the relationship between perceived family distress and adolescent life satisfaction are given by studies [31], [32] that emphasize contribution of 
family structure and parent-child communication.

The results also show that perceived family distress in female teenagers has a stronger correlation with selfforgiveness and forgiveness of situations compared to male teenagers. Furthermore, perceived family distress in male teenagers is significantly related to the forgiveness of others, but not in female teenagers. Previous research has confirmed the association between family situations with empathy and prosocial behavior in adolescents [33]. Forgiveness as a form of prosocial behavior directed toward relationships with others [34], [35] seems to be more prominent in male than female teenagers. This result is surprising when considered from the viewpoint that empathy as a psychological construct that is often associated with forgiveness, is actually higher in women than men $[36,37]$. Especially with age, empathy in boys decreases in adolescents [38]. As in [39], reports that female adolescents are more affected by relationship stressors. Furthermore, previous research explains that prosocial behavior is more clearly demonstrated by male teenagers because of its impact on improving social status and is associated with narcissism [40]. Besides being suspected to be related to the high level of forgiveness towards others as a form of prosocial behavior to improve social status, forgiveness of self and situations seem to indicate weak control in male teenagers who might weaken their status. In male teenagers, narcissism is more related to social dominance and increases control over others [41]. On the other hand, researchers suspect that the conditions of female teenagers who are more introspective and have negative self-concept tendencies compared to male teenagers [42], [43] in making forgiveness of self and situations more valued can help overcome those things. This is also in line with the results in the current study of the correlation inter- positive psychological variables, namely that compared to male teenagers, forgiveness in female teenagers (either in general or based on its dimensions) plays a greater role for hope and satisfaction with life.

Agency subscale of hope is negatively and significantly associated with perceived family distress, but this does not happen in the pathway's subscale of hope. Both male and female teenagers do not have a significant relationship between perceived family distress and the pathways subscale of hope. Prominent differences of implications in the two subscales of hope have been studied previously [44]. This may occur due to the development of the prefrontal cortex in adolescents which is much slower than the limbic system so that they experience very strong emotions which are not sufficiently supported by the development of the prefrontal cortex which is expected to help control the passion [45]. In other words, the aspirations of adolescents are not accompanied by careful planning. Elkind's theory [46] of the apparent hypocrisy characteristic of adolescents which proposes the ability to conceive ideas and the inability to relate ideas to behavior in in line with this. More specifically, hope and its agency subscale in male teenagers are not significantly related to perceived family distress, but those correlations in female teenagers show significant relationships. Agency subscale is a reciprocally derived sense of successful agency (goaldirected determination) [17]. If this is not compensated by pathways subscale (planning to meet goals) in female teenagers, then this may be related to the tendency female teenagers to use more emotion-focused coping than problem-focused coping [47]. Meanwhile, the absence of a correlation between perceived family distress in male teenagers with hope and it's both subscales is also supported by the results of study [47] that is, male teenagers do not use more emotion-focused coping or problem-focused coping. Reference [48] also explains that female teenagers reported higher use of certain kinds of coping strategies, compared to males.

\section{CONCLUSION}

The results of the current study enrich previous studies on how perceptions of family situations contribute to forgiveness, hope, and life satisfaction, namely in terms of perceived family distress among adolescents. Correlations between perceived family distress and the three positive psychological variables in this study (also their dimensions and subscales) are not simple when calculating sex. The typical characteristics of adolescents are also thought to have a role. The dynamics of the results are a strong reason for the development of further research to consider the instrument of perceived family distress since the instrument used in this study is a single item scale. The diversity of subject characteristics also needs to be considered to see how they affect the positive psychological constructs in general, along with their dimensions and subscales to confirm the arguments given in the discussion of this study.

\section{ACKNOWLEDGMENT}

This research was supported by the DIPA PNBP funding Fiscal Year 2019 of the Faculty of Psychology, Diponegoro University.

\section{REFERENCES}

[1] K. C. Bronk, P. L. Hill, D. K. Lapsley, T. L. Talib, and H Finch, "Purpose, hope, and life satisfaction in three age groups," J. Posit. Psychol., vol. 4, no. 6, pp. 500-510, 2009.

[2] J. M. Chamberlain and D. A. F. Haaga, "Unconditional selfacceptance and psychological health," J. Ration. Cogn. Ther. vol. 19, no. 3, pp. 163-176, 2001.

[3] M. Szcześniak and E. Soares, "Are proneness to forgive, optimism and gratitude associated with life satisfaction?," Polish Psychol. Bull., vol. 42, no. 1, pp. 20-23, 2011.

[4] M. V. Batik, T. Y. Bingol, A. F. Kodaz, and R. Hosoglu, "Forgiveness and subjective happiness of university students," Int. J. High. Educ., vol. 6, no. 6, pp. 149-162, 2017

[5] K. Hassan, S. Sadaf, A. Saeed, and A. Idrees, "Relationship between hope, optimism and life satisfaction among adolescents," Int. J. Sci. Eng. Res., vol. 9, no. 10, pp. 1452$1457,2018$.

[6] D. C. Widyasari and Y. M. S., "The prevalence of psychological distress among adolescents: An initial study of adolescents' mental health in Malang, Indonesia," in Advances in Social Science, Education and Humanities Research, 2019, vol. 304, no. ACPCH 2018, pp. 386-389.

[7] J. C. Karremans, P. A. M. Van Lange, J. W. Ouwerkerk, and E.

S. Kluwer, "When forgiving enhances psychological wellbeing: The role of interpersonal commitment," J. Pers. Soc. Psychol., vol. 84, no. 5, pp. 1011-1026, 2003.

[8] S. Y. Kwok, L. Cheng, and D. F. Wong, "Family emotional support, positive psychological capital and job satisfaction among Chinese white-collar workers," J. Happiness Stud., vol. 16 , no. 3 , pp. 561-582, 2015. 
Y. Yang, M. Zhang, and Y. Kou, "Self-compassion and life satisfaction: The mediating role of hope," Pers. Individ. Dif., vol. 98, pp. 91-95, 2016.

[10] A. Rahmandani, Y. F. La Kahija, H. Sakti, and L. N. Ardhiani, "Exploring perceived family distress and negative emotional states among indonesian adolescents," Int. J. Psychosoc. Rehabil., vol. 24, no. 1, pp. 1407-1419, 2020.

[11] D. Knopf, M. J. Park, and T. P. Mulye, "The mental health of adolescents: A national profile, 2008," 2010.

[12] D. Garcia and T. Archer, "Adolescent life satisfaction and well- being,” J. Altern. Med. Res., vol. 4, no. 3, pp. 271-279, 2012.

[13] S. Maryati, "Factors that influence community preferences in choosing a state vocational high school in Semarang city (Faktor- faktor yang mempengaruhi preferensi masyarakat dalam memilih sekolah menengah kejuruan negeri $(\mathrm{smkn}) \mathrm{di}$ kota Semarang)," Diponegoro University, 2009.

[14] J. A. Weiss and Y. Lunsky, "The Brief Family Distress Scale: A measure of crisis in caregivers of individuals with autism spectrum disorders," J. Child Fam. Stud., vol. 20, no. 4, pp. 521-628, 2011.

[15] L. Y. Thompson et al., "Dispositional forgiveness of self, others, and situations," J. Pers., vol. 73, no. 2, pp. 313-360, 2005.

[16] F. I. García-vázquez, A. A. Valdés-cuervo, B. Martínezferrer, and L. G. Parra-pérez, "Forgiveness, gratitude, happiness, and prosocial bystander behavior in bullying," Front. Psychol., vol. 10, no. January, 2020.

[17] C. R. Snyder, S. C. Sympson, F. C. Ybasco, T. F. Borders, M. A. Babyak, and R. L. Higgins, "Development and validation of the State Hope Scale," J. Pers. Soc. Psychol., vol. 70, no. 2, pp. 321- 335, 1996.

[18] C. I. Bryce, B. L. Alexander, A. M. Fraser, and R. A. Fabes, "Dimensions of hope in adolescence: Relations to academic functioning and well-being," Psychol. Sch., 2019.

[19] E. Diener et al., "The Satisfaction With Life Scale," J. Pers. Assess., vol. 49, no. 1, pp. 71-75, 1985.

[20] B. Schnettler et al., "Satisfaction with life, family and food in adolescents: Exploring moderating roles of family-related factors," Curr. Psychol., 2020.

[21] W. Pavot and E. Diener, "Review of the Satisfaction With Life Scale," Soc. Indic. Res. Ser., pp. 101-117, 2009.

[22] F. Neto, "The Satisfaction with Life Scale: Psychometrics properties in an adolescent sample," J. Youth Adolesc., vol. 22, no. 2, pp. 125-134, 1993.

[23] H. Akoglu, "User's guide to correlation coefficients," Turkish J. Emerg. Med., vol. 18, no. 3, pp. 91-93, 2018.

[24] C. León-Moreno and D. Musitu-Ferrer, "Family communication patterns, school and family self-concept, and motivation of revenge among adolescents (Estilos de comunicación familiar, autoconcepto escolar y familiar, y motivación de venganza en adolescents)," Eur. J. Investig. Heal. Psychol. Educ., vol. 9, no. 1, pp. 51-58, 2019

[25] K. Kissil, "Attachment-based family therapy for adolescent self- injury," J. Fam. Psychother., vol. 22, no. 4, pp. 313327,2011 .

[26] N. Watanabe, "Forgiveness in Japanese children and adolescents: Dispositional, emotional, and parental influence," George Mason University, 2011.

[27] M. Girard and E. Mullet, "Development of the forgiveness schema in adolescence," Univ. Psychol., vol. 11, no. 4, pp. 1235-1244, 2012.

[28] F. Jafari, Z. Yousefi, and G. Manshaee, "Mothers characters and adolescence depression," Open J. Depress., vol. 3, no. May, pp. 45-51, 2014.

[29] A. Sharabi, U. Levi, and M. Margalit, "Children's loneliness, sense of coherence, family climate, and hope: developmental risk and protective factors," J. Psychol., vol. 146, no. 1-2, pp. 61-83, 2012

[30] S. A. Stoddard, B. J. Mcmorris, and R. E. Sieving, "Do social connections and hope matter in predicting early adolescent violence?," Am. J. Community Psychol., vol. 48, no. 3-4, pp. 247-256, 2011
[31] K. A. Levin and C. Currie, "Family structure, mother-child communication, father-child communication, and adolescen life satisfaction," Health Educ., vol. 110, no. 3, pp. 152-168, 2010.

[32] K. A. Levin, L. Dallago, and C. Currie, "The association between adolescent life satisfaction, family structure, family affluence and gender differences in parent-child communication," Soc. Indic. Res., vol. 106, no. 2, pp. $287-$ 305, 2012.

[33] H. Yoo, X. Feng, and R. D. Day, “Adolescents' empathy and prosocial behavior in the family context: A longitudinal study," J. Youth Adolesc., vol. 42, no. 12, pp. 1858-1872, 2013.

[34] C. R. Snyder and S. J. Lopez, Positive psychology, the scientific and practical explorations of human strengths. California: Sage Publications, Inc., 2007.

[35] S. J. Lopez, J. T. Pedrotti, and C. R. Snyder, Positive psychology, the scientific and practical explorations of human strengths. Third edition, 3rd ed. California: Sage Publications, Inc., 2015.

[36] D. I. Lestari and I. M. Agung, "Empathy and forgiveness among college students of faculty of psychology at the Suska Riau State Islamic University (Empati dan pemaafan pada mahasiswa fakultas psikologi UIN Suska Riau)," Stud. Insa. vol. 4, no. 2, pp. 137-146, 2016.

[37] D. Angraini and H. Cucuani, "Relationship of the quality of friendship and empathy in the forgiveness of late adolescents (Hubungan kualitas persahabatan dan empati pada pemaafan remaja akhir)," J. Psikol., vol. 10, no. 1, pp. 18-24, 2014.

[38] K. J. Michalska, K. D. Kinzler, and J. Decety, "Age-related sex differences in explicit measures of empathy do not predict brain responses across childhood and adolescence," Dev. Cogn. Neurosci., vol. 3, pp. 22-32, 2013.

[39] B. E. Compas, J. K. Connor-Smith, H. Saltzman, A. H. Thomsen, and M. E. Wadsworth, "Coping with stress during childhood and adolescence: Problems, progress, and potential in theory and research," Psychol. Bull., vol. 127, pp. $87-127,2001$

[40] R. Kauten and C. T. Barry, "Do you think I'm as kind as I do? The relation of adolescent narcissism with self- and peerperceptions of prosocial and aggressive behavior," Pers. Individ. Dif., vol. 61-62, pp. 69-73, 2014

[41] A. Reijntjes et al., "Narcissism, bullying, and social dominance in youth: A longitudinal analysis," J. Abnorm. Child Psychol., vol. 44, no. 1, pp. 63-74, 2015.

[42] C. Marius, R. L. Claudia, G. E. Florina, and P. Densia, "Gender differences in adolescents' physical selfperceptions," Sci. Movement, Heal., vol. 11, pp. 292-296, 2011.

[43] E. K. Beasley and A. C. Garn, "An investigation of adolescent girls' global self-concept, physical self-concept, identified regulation, and leisure-time physical activity in physical education," J. Teach. Phys. Educ., vol. 32, no. 3, pp. 237-252, 2013

[44] S. C. Roesch, K. M. Duangado, A. A. Vaughn, A. A. Aldridge, and F. Villodas, "Dispositional hope and the propensity to cope: A daily diary assessment of minority adolescents," Cult. Divers. Ethn. Minor. Psychol., vol. 16, no. 2, pp. 191-198, 2010.

[45] S. J. Blakemore and K. L. Mills, "Is adolescence a sensitive period for sociocultural processing?," Аnпи. Rev. Psychol., vol. 65 , no. 1, pp. 187-207, 2014.

[46] D. Elkind, Development of the Child. New York, NY: Wiley, 1978.

[47] A. G. Horwitz, R. M. Hill, and C. A. King, "Specific coping behaviors in relation to adolescent depression and suicidal ideation," J. Adolesc., vol. 34, no. 5, pp. 1077-1085, 2011.

[48] E. Cicognani, "Coping strategies with minor stressors in adolescence: Relationships with social support, self-efficacy, and psychological well-being," J. Appl. Soc. Psychol., vol. 41 , no. 3, pp. 559-578, 2011 